\title{
Prevalence and risk factors for group B streptococcal colonization in pregnant women in northern India
}

\author{
Fareha Khatoon $^{1}$, Aruna Nigam ${ }^{2}$, Neela Rai Sharma ${ }^{3}$, Reena Srivastava ${ }^{3}$, \\ Renu Sangal ${ }^{3}$, Najma Malik $^{3}$
}

\author{
${ }^{1}$ Department of Obstetrics and Gynecology, ELMCH, Lucknow, Uttar Pradesh, India \\ ${ }^{2}$ Department of Obstetrics and Gynecology, HIMSR, Jamia Hamdard, New Delhi, India \\ ${ }^{3}$ Department of Obstetrics and Gynecology, BRD Medical College, Gorakhpur, Uttar Pradesh, India
}

Received: 27 September 2016

Accepted: 24 October 2016

\author{
*Correspondence: \\ Dr. Fareha Khatoon, \\ E-mail: faarehak@gmail.com
}

Copyright: ( $)$ the author(s), publisher and licensee Medip Academy. This is an open-access article distributed under the terms of the Creative Commons Attribution Non-Commercial License, which permits unrestricted non-commercial use, distribution, and reproduction in any medium, provided the original work is properly cited.

\begin{abstract}
Background: Group B Streptococci are a constituent of the normal vaginal bacterial microflora. During pregnancy there are optimal conditions for GBS multiplication in the vagina, which may have serious consequences for both the mother and her child. Aims: To study the prevalence of Group B Streptococcal colonization in pregnant women in Eastern U.P and antibiogram of the isolates (GBS) with a view to determine the pattern of antibiotic resistance. Study design: Observational cross-sectional study.

Methods: 300 pregnant women admitted at term gestation or with preterm labour were recruited in the study. Swabs were taken from the lower one third of vagina and the anorectal region and then placed in Todd-Hewitt Broth, an enrichment media for GBS and later subcultured on blood agar. It was then examined for beta haemolytic colonies. The Chi-square test and Fisher's exact test were used to compare the two groups. $\mathrm{P}$ values $<0.05$ were considered statistically significant.

Results: The culture positivity rate of GBS was $2 \%$. Significant association was found with increasing age, gravidity (Age $>30$ years, $\mathrm{p}<0.012$; Gravida $>3, \mathrm{p}<0.03$ ), and higher socioeconomic status $(\mathrm{p}<0.007)$. No significant association found between GBS colonization and level of education, urban/rural area and gestational age. Prevalence of GBS in PROM was 5.6\% and in preterm labour 3.3\%. All the isolates were sensitive to ampicillin and resistant to gentamicin. Conclusions: GBS colonization among pregnant women was significantly correlated with age, parity and socioeconomic status. In pregnancy GBS colonization can cause premature rupture of membranes and preterm labour.
\end{abstract}

Keywords: Group B streptococcus, Pregnancy, Puerperium

\section{INTRODUCTION}

The Group-B Streptococci (GBS) are known to cause a wide variety of infections in adults, but clinical interest in these bacteria mainly relates to their ability to cause serious neonatal illness, especially meningitis and sepsis. The primary risk factor for neonatal GBS infection is the maternal colonisation with the organism. This is also the basis of preventive strategies in western countries. According to studies, the GBS vaginal colonisation rates in Europe ranged from $6.5 \%$ to $36 \%$ which is similar to United States where colonization is reported from $10-30 \%$ in pregnant women. ${ }^{1,2}$ However in developing countries like India, the problem has not been adequately studied and there are only a few studies available. ${ }^{3}$

GBS is a gram positive diplococcus that is beta haemolytic, meaning that it shows complete haemolysis on blood agar plates. GBS also produces type specific polysaccharides antigens that encapsulate the organism 
and allow its classification into five serotypes. All the capsular polysaccharides have a terminal sialic acid side chain which is their major antigenic determinant. GBS are a constituent of the normal vaginal bacterial microflora, which often do not demonstrate any clinical symptoms. Approximately $10 \%-30 \%$ of pregnant women are colonized with GBS in the vagina or rectum. ${ }^{4,5}$ GBS colonization during pregnancy can be transient, intermittent, or persistent. ${ }^{6}$ The gastrointestinal tract serves as the primary reservoir for GBS and is the likely source of vaginal colonization. Heavy colonization, defined as culture of GBS from direct plating rather than from selective broth only, is associated with higher risk for early-onset disease in newborns. ${ }^{7}$ Although earlyonset GBS disease in newborns has become relatively uncommon in western countries in recent years due to effective screening programmes and intrapartum antibiotic prophylaxis strategies, however the rates of maternal GBS colonization remain unchanged since the 1970s. ${ }^{8}$ The Centres for Disease Control (CDC) recommends that all pregnant women should be screened at 35-37 weeks of gestation for vaginal and rectal GBS colonization in developed countries whereas there are no guidelines regarding this in the developing countries like India.

The present study was carried out to study the prevalence and risk factors for Group B Streptococcal colonization in pregnant women in Eastern Uttar Pradesh and antibiogram of the isolates (GBS) with a view to determine the pattern of antibiotic resistance.

\section{METHODS}

This was an observational cross sectional study conducted in the Department of Obstetrics and Gynaecology at Nehru Hospital, B.R.D. Medical College, Gorakhpur from October 2011 to October 2012. 300 pregnant women admitted at term gestation or with preterm labour were recruited in the study after written informed consent. The pregnant women who were on antibiotic intervention in the last trimester of pregnancy were excluded from the study. All pregnant women were subjected to complete history including demographic profile, obstetric history and general physical examination and obstetric examination.

Specimens to study the microbiological environment of vagina and the anal canal were collected with the help of serum-coated cotton-tipped swab sticks for culture. One swab was taken from the lower one third of vagina and second swab was taken from the anorectal region. The swabs were placed in Todd-Hewitt Broth, an enrichment media for GBS and later subcultured on blood agar. GBS strains were identified according to their morphology, beta hemolysis and characteristics biochemical reactions.

Data entry and analysis were done using statistical software SPSS for Windows Version 20.0. The Chisquare test and Fisher's exact test were used to compare the two groups. $\mathrm{P}$ values $<0.05$ were considered statistically significant.

\section{RESULTS}

Table 1 describes the prevalence of GBS infections with respect to age, parity and socio-economic status. Significant association was found with increasing age (Age>30 years, p <0.012), socioeconomic status (significantly more prevalent in upper socioecomic status, $\mathrm{p}<0.007$ ) and in higher gravidity (Gravida >3, $\mathrm{p}<0.03$ ). No association was found with urban/rural population $(\mathrm{p}=0.110)$.

Among the 6 GBS colonized mothers, GBS was isolated in two cases from vagina $2 / 6(33.33 \%)$, in two cases from rectum $(33.33 \%)$ and in two cases from both vagina and rectum $(33.33 \%)$. Prevalence of other micro-organisms isolated from the anogenital region was Staplylococcus aureus (24\%), E. coli (8.3\%), Candida spp. (7\%), Klebsiella $(5.7 \%)$, Streptococcus pyogenes $(1 \%)$ and other bacteroids $(1.7 \%)$.

Table 1: Prevalence and correlates of GBS colonization among pregnant women.

\begin{tabular}{|c|c|c|c|c|c|}
\hline Age (years) & GBS positive cases & GBS negative cases & Total & Prevalence \% & Test of significance \\
\hline $15-25$ & 1 & 178 & 179 & $0.6 \%$ & \multirow{4}{*}{$\begin{array}{l}X^{2}=11.0 \\
p=0.012\end{array}$} \\
\hline $25-30$ & 2 & 87 & 89 & $2.2 \%$ & \\
\hline $30-35$ & 2 & 21 & 23 & $8.6 \%$ & \\
\hline$>=35$ Years & 1 & 8 & 9 & $11.1 \%$ & \\
\hline \multicolumn{6}{|l|}{ Socio economic status } \\
\hline Upper middle class & 2 & 14 & 16 & 12.5 & \multirow{3}{*}{$\begin{array}{l}X^{2}=9.885 \\
p=0.0071\end{array}$} \\
\hline Lower middle class & 3 & 159 & 162 & 1.9 & \\
\hline Lower class & 1 & 121 & 122 & 0.8 & \\
\hline \multicolumn{6}{|l|}{ Gravida } \\
\hline G 1 & 1 & 121 & 122 & $0.8 \%$ & \multirow{3}{*}{$\begin{array}{l}X^{2}=6.801 \\
p=0.0334\end{array}$} \\
\hline G-2 & 0 & 76 & 76 & $0.0 \%$ & \\
\hline$\geq \mathrm{G} 3$ & 5 & 97 & 102 & $4.9 \%$ & \\
\hline
\end{tabular}


All the GBS isolates were found to be sensitive to ampicillin followed by erythromycin and penicillin. Resistance was seen with gentamicin, tetracycline and Kanamycin.
Out of the total 6 positive cases, 1 woman presented with preterm rupture of membrane and 1 presented with preterm labour (Table 2).

Table 2: Prevalence of complication following GBS anogenital colonization during pregnancy.

\begin{tabular}{|lllll|l|}
\hline Complications & $\begin{array}{l}\text { GBS positive } \\
\text { cases }\end{array}$ & $\begin{array}{l}\text { GBS negative } \\
\text { cases }\end{array}$ & $\begin{array}{l}\text { Total cases with } \\
\text { complication }\end{array}$ & Prevalence (\%) \\
\hline Incidence of PROM & 1 & 17 & 18 & 5.6 & $\mathbf{X}^{2}=0.6897$ \\
\hline Incidence of preterm labour & 1 & 29 & 30 & 3.3 & 0.7083 \\
\hline Fever during pregnancy & 0 & 12 & 12 & 0.0 \\
\hline
\end{tabular}

Table 3: Relation between colonization of GBS and adverse event in puerpurium.

\begin{tabular}{|c|c|c|c|c|c|}
\hline $\begin{array}{l}\text { Adverse events in } \\
\text { puerperium }\end{array}$ & $\begin{array}{l}\text { GBS } \\
\text { positive cases }\end{array}$ & $\begin{array}{l}\text { GBS negative } \\
\text { cases }\end{array}$ & $\begin{array}{l}\text { Total cases with } \\
\text { adverse events }\end{array}$ & Prevalence (\%) & \multirow{4}{*}{$\begin{array}{l}X^{2}=0.5584 \\
P=0.7564\end{array}$} \\
\hline Fever & 0 & 23 & 23 & 0 & \\
\hline UTI & 1 & 48 & 49 & 2.04 & \\
\hline Sepsis & 0 & 4 & 4 & 0 & \\
\hline
\end{tabular}

The density of maternal colonization with GBS at delivery was found to be an important predictor of neonatal outcome. Out of 6 positive cases, 2 cases were colonized at both vagina and anorectal region and neonatal outcome was stillbirth. In 2 cases where GBS was present in vagina only, one woman had preterm rupture of membrane and one woman had preterm labour. In two cases, GBS was present in anorectal region and it was neither associated with any maternal complication nor neonatal complication. Table 3 depicts the puerperal complications.

\section{DISCUSSION}

Epidemiological studies in India have shown lower colonisation and infection rates in general. The reported low prevalence of GBS infection from Indian subcontinent may be due to the low rate of institutional deliveries and inadequate screening. ${ }^{9}$ However few authors from India reported similar rates as in United States attributing it to the adequate culture techniques and microbiological media. ${ }^{10}$

Maternal colonization by GBS was observed to range from $4 \%$ to $40 \%$ in several studies conducted worldwide. $^{11-13}$

In this study, the culture positivity rate of Group-B streptococcus was $2 \%$. The other Indian studies have quoted the similar rates $(2.35$ and $2.52 \%) .{ }^{14,15}$ Similar rates have also been reported by few other authors from the developing world besides India. ${ }^{15-17}$

In this study prevalence of Group-B Streptococcus colonization was found to be more in women with age greater than 30 years of age. A study from Trinidad by Orrett FA et al showed a significant trend of increasing prevalence with increasing age. ${ }^{18}$ However Javanmanesh $F$ et al found no significant association with age and education. ${ }^{19}$

The prevalence of the GBS colonization was found to be higher in socially privileged class in our study which was comparable to the study from New Zealand who also found increased risk of GBS colonization in socially advantaged population. ${ }^{20}$ Although most of the studies have found increased colonization rate with increasing parity comparable to our study but Dechen TC et al has found no association between gravid and GBS colonization. $^{14,21,22}$

All the isolates were found to be sensitive to ampicillin, followed by erythromycin and penicillin. Resistance was seen with gentamicin followed by tetracycline and Kanamycin. This pattern was similar to other studies. ${ }^{23,24}$

The density of maternal colonization at delivery was found to be an important predictor of vertical transmission of GBS to the neonate. It was observed that if Group-B Streptococcus was carried in both vaginal and anorectal region, then the neonatal outcome was worse, resulting in stillbirths.

\section{CONCLUSION}

This study showed the prevalence of GBS colonization among pregnant women to be $2 \%$ and all the isolates were found to be ampicillin sensitive. GBS was significantly correlated with age, parity and socioeconomic status. In pregnancy GBS colonization can cause PROM and preterm labour. Heavy colonization can lead to intrauterine death. There is a need to carry out the study in the community to know the true prevalence in the general population. 
Funding: No funding sources

Conflict of interest: None declared

Ethical approval: The study was approved by the Institutional Ethics Committee

\section{REFERENCES}

1. Schrag S, Gorwitz R, Fultz-Butts K, Schuchat A. Prevention of perinatal group B streptococcal disease. Revised guidelines from CDC. MMWR Recomm Rep. 2002;51(11):1-22.

2. Barcaite E, Bartusevicius A, Tameliene R, Kliucinskas M, Maleckiene L, Nadisauskiene R. Prevalence of maternal group B streptococcal colonisation in European countries. Acta Obstet Gynecol Scand. 2008;87:260-71.

3. Shet A, Ferrieri P. Neonatal and maternal group B streptococcal infections: A comprehensive review. Indian J Med Res. 2004;120:141-50.

4. Yancey MK, Schuchat A, Brown LK, Ventura VL, Markenson GR. The accuracy of late antenatal screening cultures in predicting genital group B streptococcal colonization at delivery. Obstet Gynecol. 1996;88:811-5.

5. Campbell JR, Hillier SL, Krohn MA, Ferrieri P, Zaleznik DF, Baker CJ. Group B streptococcal colonization and serotype-specific immunity in pregnant women at delivery. Obstet Gynecol. 2000;96(4):498-503.

6. Hansen SM, Uldbjerg N, Kilian M, Sorensen UB. Dynamics of Streptococcus agalactiae colonization in women during and after pregnancy and in their infants. J Clin Microbiol. 2004;42:83-9.

7. Yancey MK, Duff P, Kubilis P, Clark P, Frentzen BH. Risk factors for neonatal sepsis. Obstet Gynecol. 1996;87:188-94.

8. Verani JR, McGee L, Schrag SJ. Prevention of perinatal group B streptococcal disease. Revised guidelines from CDC. MMWR Recomm Rep. 2010;59(10):1-23.

9. National Family Health Survey (NFHS-3), 2005-06: India: Volume 1. Mumbai: IIPS. Available from: http:/www.nfhsindia.org/India.html [Last accessed on 2015 Oct 15]

10. Stoll BJ, Schuchat A. Maternal carriage of group B streptococci in developing countries. Pediatr Infect Dis J. 1998;17:499-503.

11. Elbaradie SM, Mahmoud M, Farid M. Maternal and neonatal screening for Group B streptococci by SCP B gene based PCR: a preliminary study. Indian J Med Microbiol. 2009;27:17-21.

12. Hickman ME, Rench MA, Ferrieri P, Baker CJ. Changing epidemiology of group B streptococcal colonization. Pediatrics. 1999;104:203-9.

13. Tswana SA, Maeland JA. Prevalence, capsular type distribution, anthropometric and obstetric factors of group B Streptococcus (Streptococcus agalactiae) colonization in pregnancy. Cent Afr $\mathrm{J}$ Med. 2000;46:115-20.

14. Sharmila V, Joseph NM, Babu TA, Chaturvedula L, Sistla S. Genital tract group B streptococcal colonization in pregnant women: a South Indian perspective. J Infect Dev Ctries. 2011;5(8):592-5.

15. Kulkarni AA, Pawar SG, Dharmadhikari CA, Kulkarni RD. Colonization of pregnant women and their newborn infants with group-B streptococci. Indian J Med Microbiol. 2001;19:1-4.

16. Shirazi M, Abbariki E, Hafizi A, Shahbazi F, Bandari M, Dastgerdy E. The prevalence of group B streptococcus colonization in Iranian pregnant women and its subsequent outcome. Int $\mathrm{J}$ Fertil Steril. 2014;7(4):267-70.

17. Yang MJ, Sun PL, Wen KC, Chao KC, Chang WH, Chen CY, et al. Prevalence of maternal group B Streptococcus colonization and vertical transmission in a low risk women in a single institute. J Chin Med Assoc. 2012;75:25-8.

18. Orrett FA, Olagundoye V. Prevalence of group B Streptococcal colonization in pregnant third trimester women in Trinidad. J Hosp Infect. 1994;27:43-8.

19. Javanmanesh F, Eshhraghi N. Prevalence of positive rectovaginal culture for group B Streptococcus in pregnant women at 35-37 weeks of gestation. Med Journal J Islam Repub Iran. 2013;27:7-11.

20. Campbell N, Eddy A, Darlow B, Stone P, Grimwood K; New Zealand GBS Consensus Working Party. The prevention of early-onset neonatal group $\mathrm{B}$ streptococcus infection: Technical report from the New Zealand GBS Consensus Working Party. N Z Medl J. 2004;117(1200):U1023.

21. Orrett FA. Colonization with Group B streptococci in pregnancy and outcome of infected neonates in Trinidad. Pediatr Int. 2003;45:319-23.

22. Dechen TC, Sumit K, Ranabir P. Correlates of vaginal colonization with group B Streptococci among pregnant women. J Globe Infect Dis. 2010;2:236-41.

23. Dutra VG, Alves VM, Olendzki AN, Dias CA, de Batos AF, Santos GA et al. Streptococcus agalactiae in Brazil: serotype distribution, virulence determinants and antimicrobial susceptibility. BMC Infect dis. 2014;14:323.

24. Lu B, Li D, Cui Y, Sui W, Huang L, Lu X. Epidemiology of group B Streptococcus isolated from pregnant women in Beijing, China. Clin Microbiol Infect. 2014;20:370-3.

Cite this article as: Khatoon F, Nigam A, Sharma NR, Srivastava R, Sangal R, Malik N. Prevalence and risk factors for group B streptococcal colonization in pregnant women in northern India. Int J Reprod Contracept Obstet Gynecol 2016;5:4361-4. 